\title{
Medicina legal y derecho en Antioquia (1914-1938) ${ }^{*}$
}

\section{Piedad del Valle Montoya*}

Recibido: 18 de abril de 2017

Enviado a pares evaluadores: 25 de abril de 2017

Aprobado por pares evaluadores: 26 de mayo de 2017

Aprobado por Comité Editorial: 23 de junio de 2017

DOI: 10.22395/csye.v6n12a7

\section{RESUMEN}

Este artículo de investigación presenta casos antioqueños, sin dejar de estudiar casos de Bogotá y Cundinamarca, que permiten entender ese horizonte de transformación que significó la regulación de la medicina legal en Colombia lo mismo que la influencia de la escuela positiva italiana y la teoría de la degeneración en los dictámenes médico-legales sobre el estado mental del acusado. Igualmente, se parte del postulado de que el derecho penal es una forma de control social, ejercido desde el orden jurídico y desde el desarrollo de saberes como la medicina legal, con implicación en los comportamientos que entraron al terreno de lo punible, como los del hombre considerado anormal. De manera que se indagará por este proceso de cambio en el orden jurídico penal colombiano entre 1914 y 1938.

Palabras clave: control social; conductas punibles; derecho penal; filosofía del derecho; historia del derecho; legislación colombiana; medicina legal.

Artículo resultado de la investigación: "El poder del saber médico en el proceso de medicalización de la Justicia en Antioquia, 1887-1914", tesis de Maestría de su autora, dirigida por Jorge Márquez Valderrama. La autora agradece la ayuda de la profesora María Fernanda Vásquez.

** Abogada de la Universidad de Medellín. Magíster en Historia de la Universidad Nacional de Colombia, sede Medellín, Colombia. Ha escrito libros y artículos en revistas nacionales e internacionales. Actualmente es investigadora independiente. Correo electrónico: piedadelvalle@yahoo.com 


\section{Legal medicine and law in Antioquia (1914-1938)}

\section{ABSTRACT}

This research article shows Antioquian cases, but also Bogotá and Cundinamarca ones, which allow understanding that transformation horizon resulting from the regulation of legal medicine in Colombia, as well as the influence of Italian positive school and the degeneration theory in medical legal expert opinions on the defendant's mental state. Likewise, it takes into consideration that criminal law is a way of social control exercised from the juridical order and from the development of knowledge such as legal medicine, which affects behaviors considered as punishable acts, as the acts of a man deemed abnor- mal. Discussions between medical doctors and lawyers of that historical moment favored the acceptance of this knowledge. The Criminal Code of 1936, in effect from 1938, replaced 1890 Criminal Code; however, this was not an easy change, still today the classical thinking is noticed, and despite that Italian positive school postulates were known in the country, they could only be partially imposed in 1936 with the new Criminal Code.

Keywords: social control; punishable behaviors; criminal law; philosophy of law; history of law; Colombian legislation; legal medicine.

\section{Medicina legal e direito em Antioquia (1914-1938)}

\section{RESUMO}

Este artigo de pesquisa apresenta casos do estado de Antioquia (Colômbia), sem deixar de estudar casos de Bogotá e Cundinamarca, que permitem entender o horizonte de transformação que significou a regulamentação da medicina legal na Colômbia bem como a influência da escola positiva italiana e a teoria da degeneração nas decisões médico-legais sobre o estado mental do réu. Além disso, parte-se do princípio de que o direito penal é uma forma de controle social, exercido sob a ordem jurídica e o desenvolvimento de saberes como a medicina legal, que afetaram comportamentos que entraram no terreno do punível, como os do homem considerado anormal.
As discussões entre médicos e advogados desse momento histórico favoreceram a apropriação desse conhecimento. O Código Penal de 1936, que entrou em vigor em 1938, substituiu o Código Penal de 1890, mas essa mudança não foi fácil, ainda se observa o pensamento clássico e, embora fossem conhecidos no país os princípios da escola positiva italiana, somente puderam impor-se, em parte, em 1936, com o novo Código Penal.

Palavras-chave: comportamentos puníveis; controle social; direito penal; filosofia do direito; história do direito; legislação colombiana; medicina legal. 


\section{Introducción}

A pesar de que algunos acontecimientos no se dieron en el país, ni en todo el territorio, ni fueron simultáneos, se articularon entre sí posibilitando parte del cambio del pensamiento colombiano, especialmente el de la medicina legal. El período va entre 1914, fecha de la regulación de la medicina legal, y 1938, fecha de la entrada en vigencia del Código Penal de 1936. Estos hechos prepararon la reforma de algunos de los conceptos que habían dominado muy especialmente el campo jurídico del derecho penal.

Es de anotar que, en este artículo, este complejo conjunto posibilita la comprensión del derecho penal como un sistema de control social conforme al cual

[...] una persona en su acción está de hecho condicionada y limitada por los grupos, por las instituciones y por la sociedad entera de la que es miembro, razones que permiten fundamentar el hallazgo de mecanismos de control tanto en las sociedades primitivas como en las complejas ciudades cosmopolitas en pleno apogeo postmoderno, materializándose en la primera de estas mediante los controles informales, mientras que en las siguientes se produce una combinación entre estos y aquellos que tienen en sus manos la tarea de concretar la disciplina social...( Aguilar, 2010).

De acuerdo con estas ideas, la pregunta de investigación es la siguiente: ¿cómo fue el proceso de cambio en el orden jurídico penal colombiano entre 1914 y 1938 a partir de la regulación de la medicina legal, y de la influencia de la escuela positiva italiana y de la teoría de la degeneración en los dictámenes médico-legales sobre el estado mental del acusado?

Desde el punto de vista metodológico es necesario precisar que se tuvo presente la legislación nacional como el Código Penal de 1890, la Constitución Nacional de 1886 y el Código Penal de 1936, ya que para esas fechas Colombia era un estado centralizado. También se utilizaron algunas fuentes primarias. La razón fundamental para utilizar distintas fuentes es que se trata de un proceso que se presentó de distintas maneras y en distintos momentos en muchas zonas del país.

Para responder la pregunta de investigación se articularon tres acontecimientos, que fueron preparatorios para que la medicina legal, los postulados de la escuela positiva italiana y la teoría de la degeneración tuvieran tanta importancia en el orden jurídico penal colombiano. Estos acontecimientos fueron:

A) La transformación de la práctica médica en Colombia y la teoría de la degeneración en el campo de las enfermedades mentales: la práctica médica denominada "científica" en este artículo, particularmente la medicina legal, especialidad que emerge en la última parte del siglo XIX, fue regulada legalmente en Colombia en 1914, y el dictamen médico legal sobre el estado mental del acusado era parte de esta especialidad. También durante el siglo 
XIX se formuló la teoría de la degeneración por parte de varios autores, siendo el más destacado Bénédict August Morel.

B) El debate conceptual y metodológico entre dos de las escuelas penales más importantes del derecho: la escuela clásica y la escuela positiva italiana y su impacto en el derecho penal colombiano. Este debate ayudó en la difusión no solo de la medicina legal, sino de la misma escuela positiva italiana y de la teoría de la degeneración.

C) La importancia del positivismo durante el siglo XIX y el siglo XX, que abarca el período comprendido entre 1914 y 1938 límite temporal de esta investigación. La comprensión del concepto de ciencia en parte de Occidente influenció a Colombia. Surgieron como dice Salcedo "ambiciosas ciencias del hombre [las cuales] partieron de la idea de que para mantener el status de ciencias y obtener tan buenos resultados prácticos y teóricos, tal y como sucedía con las ciencias, debían proceder bajo la filosofía y metodología de las ciencias naturales". Este tipo de pensamiento se conoce como "positivismo" (Salcedo, 2002, p. 25).

Los hechos anteriores posibilitaron modificaciones que afectaron tanto a la medicina legal como al derecho, e impactaron comportamientos que entraron al terreno de lo punible, como los del hombre considerado anormal.

\section{La transformación de la práctica médica en Colombia y la teoría de la degeneración en el campo de las enfermedades mentales}

El dictamen médico-legal sobre el estado mental del acusado en un proceso penal muestra un cambio filosófico en Colombia. El sentido positivista de cientificidad que dominó particularmente a Occidente durante el siglo XIX y se extendió hasta buena parte del siglo XX en muchas ciencias impacta el período de este trabajo comprendido entre 1914 y 1938. En este campo, la medicina había realizado prodigiosas conquistas: basta recordar la importancia del pasterianismo. Sin embargo, desde 1876, fecha de la publicación de "El hombre criminal" de César Lombroso, se empezaron a quebrar con fuerza algunos cimientos del derecho penal clásico en muchos países. Entre tanto, en Colombia según del Valle (2010), la medicina legal empezó a ser reconocida en el campo judicial y muchos procesos contaban con un dictamen médico legal desde finales del siglo XIX. El saber médico "científico" era ampliamente reconocido entre los funcionarios judiciales. No obstante, solo hasta la Ley 53 de 1914, se instituyó el Servicio Nacional de Medicina Legal.

La nueva ley creaba la especialidad de médico legista y exigía, entre otros requisitos, obtener el título de médico cirujano. Además, este nuevo servicio se 
integró al poder judicial. Este estatuto fortaleció la posición del perito médico en la dinámica probatoria del enjuiciamiento criminal. Se podría afirmar que la práctica médica "científica" se impuso. Este proceso fue muy lento y la misma ley posibilitó la concurrencia entre las distintas prácticas médicas por largo tiempo ${ }^{1}$. Según Márquez (2011), una estadística oficial data de 1934 y en ella la categoría "médicos" aparece subdividida en diplomados, permitidos, licenciados, especialistas y homeópatas permitidos; en otra categoría figuran las parteras. Por otra parte, es importante recordar que, conforme al mismo Márquez, se creó la Junta Central de Higiene, aparato sanitario estatal creado en el momento de inserción de Colombia en la economía mundial. En 1914 se volvió a crear esta Junta con el nombre de Consejo Superior de Sanidad.

Para Márquez (2016) a partir de 1914 con la vigencia de las leyes 83 y 84 de la misma fecha se legitimaron más las funciones de los médicos ["científicos"] como higienistas y educadores.

Gracias a la reforma sanitaria y al fortalecimiento de un proceso de medicalización, la participación de un sector cada vez más amplio de médicos en el gobierno de la salud les otorgó más poder y consolidó el que ya detentaba la medicina universitaria ["científica"] como oferta terapéutica legítima para el país. Esta medicina fue investida con nuevos poderes: la presencia de los médicos comenzó a popularizarse con la extensión de prácticas como la vacunación, la institución de los "médicos oficiales" en los municipios y de los "médicos de zona" (rurales); asimismo, las oficinas locales de higiene controlaban en parte la vida cotidiana y habían aparecido nuevas instituciones ligadas a la salud como dispensarios y gotas de leche, que se sumaron a los hospitales ya existentes. La reforma sanitaria iniciada en 1914 abrió un campo de consolidación de la profesión médica. Sin embargo, las prácticas irregulares continuarían siendo un motivo de tensiones durante toda la primera mitad del siglo XX (Márquez, 2016, p. 87).

Ahora bien, la medicina "científica" tenía entre sus especialidades la medicina legal, y en el evento de un dictamen médico legal, por ejemplo, en un caso de envenenamiento, posiblemente se acudía al laboratorio de toxicología y eran muchos los conocimientos científicos que un funcionario podía tener presentes al momento de resolver judicialmente. En cambio, en un dictamen médico-legal sobre el estado mental, que muchas veces recaía sobre el sindicado o acusado, dejaba al descubierto temas estructurales, que tenían relación con importantes concepciones jurídicas algunas asentadas en la filosofía clásica. Es posible que este hecho explique inicialmente las diferencias que, según Vásquez (2015), se presentaron entre médicos ["científicos"] y abogados a propósito de estos dictámenes.

La práctica médica fue regulada en varias ocasiones y la ley establecía las condiciones en las cuales podían ejercer su profesión quienes no tenían título. Algunas de esas normas son: la 83 de 1914; la Ley 67 de 1920; la Ley 39 de 1920; la Ley 85 de 1922; la Ley 35 de 1929 y la Ley 67 de 1935. 
Además, uno de los objetos de la medicina legal era la locura, llamada también demencia o alienación. Este asunto ameritó un tratamiento especial, por esto algunos médicos legistas publicaron obras dedicadas solo a este tema, como fue el caso del médico Carlos E. Putnam. La modalidad del dictamen médico-legal era fundamental en algunos procesos penales y ya el Código Penal colombiano de 1890 en su artículo 29, había relacionado entre las personas excusables y, por lo tanto, exentas de pena alguna, a quienes se encontraran en estado de verdadera demencia o locura al tiempo de cometer la acción, o privados del uso de su razón.

Igualmente, y según Vásquez (2015, p. 87), en "el ámbito jurídico no existía una homogeneidad en la aceptación de las enfermedades mentales como prueba de irresponsabilidad penal". Asimismo (2015, p. 108). "Desde los primeros años del siglo XX ambos estudios serán complementarios. Si en los últimos años del siglo XIX es la medicina legal la que motiva los estudios clínicos ${ }^{2}$ sobre las enfermedades mentales, desde el siglo XX los estudios clínicos desarrollados en el país permiten ilustrar la práctica médico legal". Se creía que conocer las enfermedades mentales ayudaba a establecer criterios de criminalidad.

Vásquez (2015) afirma que el conocimiento de las enfermedades mentales estaba muy unido a la medicina legal y fue cada vez más importante. Las transformaciones en torno a la idea de la locura empezaron a abrir el campo de la clínica psicopatológica. En Colombia se evidencia, por ejemplo, en el texto de Leoncio Barreto, publicado en Bogotá, en 1890. Pero el texto que fue una guía en asuntos médico legales en las primeras décadas del siglo XX fue el Tratado práctico de medicina legal en relación con la legislación penal y procedimental del país de Carlos E. Putnam, también publicado en Bogotá, en 1908. Según Caponi (2009), la teoría de la degeneración posibilitó patologizar los más variados comportamientos y creó un marco explicativo para la enfermedad mental. Por otra parte, afirma Caponi que desaparecieron las diferencias entre la alienación mental, locura o demencia y las degeneraciones menores, donde estas se entendían como desvíos físicos o morales de formas primitivas. La eliminación de las diferencias permitió que se agruparan en un mismo espacio clasificatorio diagnósticos diferentes, que incluyeron variados desórdenes de comportamiento, entre ellos algunas conductas cotidianas. Según Caponi, lo anterior posibilitó que las ideas de peligro, entre otras, asociadas en algunos casos a la figura del loco y a la locura, se extendieran a nuevos sujetos, que se integraron a una red correctiva.

A estos sujetos se les denominó los "anormales". En la teoría de la degeneración es determinante el cerebro, que predispone [es el que permite alegar el

2 Medicina práctica realizada en muchas ocasiones en los hospitales. 
determinismo]. Vásquez (2015) afirma que el discurso de Morel es fuertemente religioso y que generalmente existe una igualdad entre alienación mental y degeneración.

En cuanto a la teoría de la degeneración, Vásquez ${ }^{3}$ (2015) afirma que existieron otras variaciones de esta teoría que fueron importantes, como la de Valentín Magnan, alumno de Morel, y la de Henri Dagonet. Según la autora lo mental era un asunto problemático y la teoría de la degeneración posibilitó un discurso médico en torno a las enfermedades mentales. De la misma manera afirma que las enfermedades mentales y la medicina legal eran campos recientes en Colombia.

Las nuevas ciencias, entre ellas algunas de las relacionadas por la escuela positiva italiana, y la teoría de la degeneración terminaron impactando algunas conductas de los acusados en los procesos penales al influir en la medicina legal.

\section{La escuela clásica del derecho y la escuela positiva italiana}

\section{Generalidades}

Existen claras diferencias entre la escuela clásica del derecho y la escuela positiva italiana, en términos de la concepción del derecho penal y la pena, su método y la existencia o inexistencia del libre albedrío, entre otros. Se podría afirmar que muchas de sus diferencias se encuentran en el terreno de la filosofía. Según Vásquez (2015) los trabajos de antropología criminal de César Lombroso, pertenecientes a la nueva escuela de derecho penal conocida como escuela positiva italiana, transformaron al demente en delincuente.

Sin embargo, en un comienzo los mismos médicos colombianos inician una crítica a los postulados de la nueva escuela, en especial a su negación del libre albedrío. Esta escuela propone la pena como tratamiento y su duración como prevención del crimen y estrategia social. Las "ciencias", en sentido positivista, como la antropología o la sociología, tan usadas por la nueva escuela, pusieron al determinismo, basado en la predisposición cerebral, en el centro de las discusiones sobre el comportamiento humano.

La Escuela Positiva italiana, cuyo principal objeto de estudio fue el criminal, nació como réplica a la Escuela Clásica, que afirmaba que el delincuente surgía como tal por autodeterminación, defendiendo la doctrina del libre albedrío. La primera, en cambio, sustentaba desde una perspectiva determinista que el delincuente no se formaba sino que nacía, aunque poco tiempo después la Escuela Positiva debió modificar esta concepción y sus máximos ponentes se vieron en la necesidad de explicar la existencia

Ver el trabajo de Vásquez, M. (2015). Degenerados, criminosos e alienados. Para uma história do conceito de degeneração na Colômbia, 1888-1950. Tese de doutorado. Programa de Pós-Graduação Interdisciplinar em Ciências Humanas. Universidade Federal de Santa Catarina (Brasil). 
de la delincuencia, a partir de condiciones tanto biológicas, como físicas y sociales...

(Calderón, 2004, p. 5).

Es de anotar que, según Calderón (2004) la escuela positiva italiana, que se seguirá llamando simplemente escuela positiva, primero se conoció con el nombre de antropología criminal, nombre creado por su fundador César Lombroso, más tarde se unieron Enrico Ferri y Raffaelle Garofalo, este último creador del término criminología, que se impuso. Pero el modelo en algunos países fue llamado Escuela Positiva Italiana.

Según Agudelo (2008), la llamada escuela clásica, estaba fundada en el derecho natural y a pesar de que existen discusiones por el uso de ese nombre, agrupaba a distintos pensadores, que se identificaban con esta denominación. Carrara $^{4}$ fue su máximo exponente. Ahora bien, para la escuela clásica, especialmente para Carrara, el derecho estaba fundado en el orden divino y era una ciencia; Agudelo también afirma que, para la escuela positiva, el derecho penal era apenas un capítulo de la sociología criminal.

Agudelo (2002) afirma que el método muestra otra de sus grandes diferencias: si la escuela clásica entendía el delito como un ente jurídico al que le correspondía el método lógico, para los positivistas importaba el delincuente, por eso proponían el método experimental, tomando los datos de otras ciencias como la psicopatología o la estadística. Esta corriente del derecho penal estaba influenciada por el gran desarrollo de la sociología, la biología, la bacteriología y la genética, entre otras. Además, por el auge de la investigación empírica y el rechazo de la filosofía como metafísica: observación, experimentación, formulación de leyes y su comprobación, fue el método que se impuso en el siglo XIX. Importaba lo comprobable, lo real, lo positivo. Según Calderón (2004), para los positivistas los hombres debían ir a la cárcel "no a purgar una pena, sino para regenerarse".

El siglo XIX estuvo signado por importantes acontecimientos como la emergencia de las ciencias humanas (Foucault, 1980) y por los cambios que se dieron en el campo del método. Porque, si algo caracterizó a la nueva escuela fue su descripción del delincuente. Lombroso, caracterizó a muchos delincuentes, entre ellos a la mujer pública o prostituta:

[Tiene] Aspiraciones a la elegancia y a las exigencias del "confort". Apetece las comidas suculentas, las golosinas, la amistad de otras como ella, fruslerías y está ávida de emociones y placeres. Precisa del vino al comer. No desea más que...distraer con algo las tardes, y una baraja de naipes con que consultar su suerte futura...ella es perezosa por excelencia y aborrece el trabajo. Imprevista hasta la exageración, la mujer pública

4 Francesco Carrara (1805-1888) fue un profesor italiano de derecho penal y el más importante representante de la escuela clásica. Es muy reconocida su obra Programa de derecho criminal. 
vive un día y otro día, sin para nada preocuparse del siguiente. Muy impresionable, llora y ríe fácilmente. Su humor es variable. Frecuentemente charlatana y expansiva, muestra cierta propensión al sentimentalismo (Lombroso, 1943, p. 26).

Lombroso, quien nació en 1835 y murió en 1909, estudió medicina en Pavía. Fue profesor de Psiquiatría, Medicina Legal y Antropología Criminal. Además, realizó descripciones que devinieron científicas sobre los delincuentes. Al asemejar los delincuentes y los epilépticos, escribió:

He observado en unos y otros la tendencia a la vagabundez, la obscenidad, pereza, orgullo del delito, grafomanía, argot, tatuaje, disimulo, falta de carácter, irritabilidad instantánea, megalomanía, intermitencia en los sentimientos, en la inteligencia y vileza; igual atraso en orden a la ecuación personal de las gentes normalmente constituidas. Idéntica vanidad, la misma propensión a contradecir y exagerarlo todo. Una común irritabilidad mordaz, carácter pernicioso, lunático y desconfiado (Lombroso, 1943, 72).

De acuerdo con Calderón (2004) los positivistas que más influencia tuvieron en Colombia fueron Lombroso y Ferri. El segundo es no solo el de mayor relevancia, sino el menos determinista. Según Agudelo (2002), la escuela clásica creía en la autodeterminación, fundamentada en el libre albedrío. Para Ferri, en cambio, el libre albedrío era una "entelequia metafísica". Según Calderón (2004) se era "responsable penalmente no por lo que se hace, sino por lo que se es, por el modo de ser", por la peligrosidad.

Esta peligrosidad social era según Goul citado en Calderón (2004. p. 7.), "la probabilidad de que el sujeto en virtud de determinadas causas sea impulsado a hechos criminosos; y por esta razón la pena retributiva es sustituida por un sistema de medidas de prevención con fines de profilaxis criminal y moralmente neutrales, proporcionadas, no a la gravedad del delito, sino a la peligrosidad del delincuente". Según Vásquez (2015, p.23) "Una de las críticas más fuertes a la nueva escuela positiva del derecho penal era su negación al libre albedrío, principio universal y moral sobre el cual se fundamentaba toda la filosofía jurídica clásica y la base de la responsabilidad".

Según Agudelo (2008), para los positivistas no existe libre albedrío, porque no existe libertad, sino necesidad. Si la libertad es negada no se puede fundar sobre ella la responsabilidad. Los positivistas no niegan la responsabilidad penal, la fundan sobre otras bases. Postulan la responsabilidad legal o social como fundamento de la acción punitiva del Estado. La escuela clásica del derecho postula que en el libre albedrío se encuentra asentada la libertad. Según Vásquez (2015, p. 158) el libre albedrío era la capacidad para distinguir el bien del mal, es decir, era "el sentido moral".

En el caso colombiano resulta importante entender el paso de la escuela clásica del derecho a la escuela positiva italiana. El Código Penal de 1890 privi- 
legió algunas instituciones proclamadas por la escuela clásica. Pero en 1914 es regulada la medicina legal y ya en el Código Penal de 1936 fue muy importante la personalidad del delincuente, por un lado, y por el otro, la defensa social. Entre tanto, el horizonte común de ambas codificaciones fue la Constitución Nacional de 1886, en la que era dominante la Iglesia Católica ${ }^{5}$. Dice la citada Constitución: "La religión Católica, Apostólica, Romana es la de la Nación; los poderes públicos la protegerán y harán que sea respetada como esencial elemento del orden social" (Rodríguez, 1927, p.10).

\section{Una historia de la escuela positiva}

Los conceptos de algunas ciencias, como la sociología o la antropología tan importantes para la nueva escuela, no se instalaron sin resistencia en el campo jurídico. Los comienzos del siglo XX informan sobre algunas de estas dificultades. El 15 de enero de 1910 el profesor de derecho penal y procedimiento en la Universidad de Roma, Arturo Rocco (1982), expuso en la "Conferencia inaugural" de una de sus cátedras, la angustia que representaban las corrientes científicas que afectaban a algunas "ciencias" como "las ciencias jurídicas". El reconocido jurisconsulto se refería especialmente a los efectos en el pensamiento jurídico de la antropología y la sociología criminales. Al realizar su análisis, Arturo Rocco acudió a citas de reconocidos jurisconsultos y con relación a la compleja situación y al proponer su propia orientación en este punto agregaba:

Existe ya, en efecto, cierto número, aunque reducido y si se quiere mínimo, de personas que, ufanándose de una hipótesis antropológica falsa o exagerada, consideran que nuestra ciencia ha perdido su razón de ser en cuanto ciencia, tanto social como jurídica... Hasta en algunos de aquellos -cuyo número constituye la mayoría- que, frente al ímpetu sociológico, mantienen aún firme la autonomía del derecho penal, la influencia de las ideas nuevas, por una parte, y por otra, el apego a los conceptos antiguos hace que la ciencia del derecho penal se salga de los confines jurídicos que naturalmente se le asignan. La producción científica contemporánea del derecho penal se caracteriza precisamente por dicho estado general de incertidumbre respecto de nuestra ciencia [...] Y así pasan hoy, por las manos de todos.... Contiene antropología, sicología, estadística, sociología, filosofía, política, es decir, de todo, menos derecho (Rocco, 1982, p. 49).

Rocco (1982, p. 50) se refería a una crisis generada por la escuela positiva, que tenía un marcado "ímpetu sociológico" y cuya confusión se manifestaba en la práctica privilegiando las pruebas y los hechos sin discusión del derecho. Citaba a Carrara para quien el derecho "tiene su origen y su norma en una

5 "Dios dio la libertad al hombre, manifestada en el libre albedrío, y la inscribió en su corazón como ley natural, con el fin de que buscara a su Creador y a la luz de su verdad fuera plenamente libre y feliz e hiciera libres y felices a sus semejantes. Tal es la verdadera libertad..." (Guerrero, 2012). Se puede observar que el concepto de la escuela clásica coincide con el de la religión católica, dominante en la Constitución de 1886, vigente en este momento. 
ley que es absoluta porque es la que establece el único orden posible para la humanidad según las previsiones y voluntad del Creador" [de donde] "subordinados de esa manera, a una norma absoluta, las leyes penales son, en sus principios cardinales, absolutas...". De manera que Rocco permite entender cómo el mundo jurídico se recomponía a comienzos del siglo XX, después de las intensas discusiones, que se presentaron desde finales del siglo XIX. Su trabajo muestra que muchos conceptos y ciencias están en emergencia, lo que explica los distintos acercamientos por parte de los juristas. Rocco observó el problema de la cientificidad planteado por el positivismo y abordó el asunto del método jurídico, partiendo, además, del supuesto según el cual la "ciencia del derecho penal" debía limitar el objeto de sus investigaciones al estudio del derecho penal positivo ${ }^{6}$. Pero acepta la importancia de ciencias como la antropología y la sociología.

\section{La trascendencia del positivismo}

Una de las corrientes filosóficas más importantes durante los siglos XIX y XX fue el positivismo que, según Moulines (1979) tenía contacto con importantes corrientes antimetafísicas. Afirma igualmente que es "una característica esencial del positivismo el presentarse como una filosofía de las ciencias empíricas..." y acude en forma permanente a las ciencias naturales.

Dicho de otro modo, sólo a partir del momento en que el intelectual occidental fue plenamente consciente de la existencia de la explicación científica del mundo como algo radicalmente nuevo y distinto de los tipos anteriores de explicación... pudo surgir la actitud "filocientífica" propia del positivismo, y su deseo de exponer ese tipo de explicación «en su estado puro», libre de las impurezas acientíficas que todavía contenía (Moulines, 1979).

Este tipo de positivismo tuvo mucha importancia y por eso de acuerdo con el mismo Moulines (1979) "el lema comtiano "orden y progreso" no solo debía aplicarse a la organización social, sino también a la ética científica" y a pesar de que el autor ubica esta clase de positivismo en la primera parte del siglo XIX se observa su resonancia en algunas ciencias todavía en las primeras décadas del siglo XX.

\section{La medicina Iegal en Antioquia}

En Antioquia en la última parte del siglo XIX, ya se conocían los postulados de la escuela positiva italiana. Calderón (2004) recuerda que, en Medellín, Miguel Martínez publicó en 1875 su tesis denominada "La criminalidad en Antioquia" de clara influencia positivista; la misma influencia se aprecia en José Vicente

$6 \quad$ Se refiere al derecho penal vigente. 
Concha, quien fue presidente de Colombia entre 1914-1918 y quien promovió una reforma penal presentando un proyecto en 1912. Concha, tuvo mucha influencia en la ciudad. Además, existían en Medellín laboratorios antropométricos ${ }^{7}$.

La aceptación de los postulados de la escuela positiva italiana fue compleja para los mismos médicos, posiblemente porque algunos de sus conceptos chocaban con principios filosóficos ampliamente aceptados. El discurso de Carlos E. Putnam (1884) en el Colegio Mayor de Nuestra Señora del Rosario muestra que el reconocido médico legista era partidario de la escuela clásica y de su filosofía penal y son muy claros sus ataques a los postulados de la escuela positiva italiana.

Pero Putnam cambió su posición como se aprecia en 1908 cuando publica la segunda parte de su Tratado práctico de medicina legal en relación con la legislación penal y procedimental del país, en el que critica los códigos Civil y Penal colombianos. Según Rojas (2015, p. 277) Putnam convertido en médico alienista, es decir, experto en enfermedades mentales, rinde un informe pericial sobre el estado mental de Braulio Ramos en 1908, dentro de un proceso penal. En efecto, para el médico legista se trataba de un caso de epilepsia, "el epiléptico era un individuo enfermo, degenerado y peligroso...". Putnam resaltó la ferocidad del crimen, acaecido en Pacho, Cundinamarca "como un-síntoma- de la anormalidad de Ramos". Rojas también señala el enorme impacto social de estos asuntos. Putnam, explicó que Ramos perdió la razón al momento de realizar el crimen. Además, según el autor, para el médico legista se evidenció la degeneración del sindicado. Vásquez (2015) afirma que en el campo médico legal los estudios clínicos de las enfermedades mentales relacionaron locura y criminalidad de forma más clara y tuvieron como soporte científico la teoría de la degeneración.

No obstante, la importancia del dictamen de Putnam radica en que este fue extendido antes de la implementación legal de muchas de las propuestas de la escuela positiva italiana, cuando se habían operado modificaciones en la medicina legal y era más fuerte la influencia de la nueva escuela y de la teoría de la degeneración. La posición de Putnam muestra la importancia de la medicina "científica" en parte de la transformación del pensamiento colombiano en este momento histórico.

[...] la aceptación de los conceptos propios de la teoría de la degeneración y de los postulados de la escuela positiva italiana dependen en parte, de la aceptación de una concepción que separa el alma del cuerpo abandonando una psicología espiritualista y sensualista, al tiempo que una visión materialista, determinista y orgánica se imponía como nueva forma de explicar las enfermedades mentales y la criminalidad (Vásquez, 2015, p. 104).

7 Eran laboratorios para la identificación judicial, que prestaban asesoramiento en la clasificación de los criminales. Ver Calderón, L. La escuela positiva italiana en la objetivación del criminal en Antioquia (18931936). Monografía para optar al título de historiadora. Universidad Nacional. Escuela de Historia y Escuela de Estudios Filosóficos y Culturales. Medellín. 
Según la misma autora (Vásquez, 2015), mediante la medicina legal se logró que médicos y jurisconsultos aceptaran esta transformación ${ }^{8}$ y consideraran la necesidad de reformar el Código Penal de 1890. Además, la discusión entre el libre albedrío ${ }^{9}$ y el determinismo, fue también mediada por la medicina legal. En esta forma estuvo despejado el camino para que la personalidad del delincuente fuera dominante y sus distintos aspectos se extendieran y se pudieran aplicar al hombre considerado anormal. La medicina a través del dictamen médico legal y en especial del dictamen médico legal sobre el estado mental del acusado tiene un lugar importante en la implementación del Código Penal de 1936.

La Academia al analizar la esencia y el fondo de los artículos mencionados ha visto con gran satisfacción que ellos revelan la tendencia moderna del Legislador Colombiano a sustituir la antigua doctrina de la vindicta pública [nota del autor] por la moderna Defensa Social de acuerdo con la antropología criminal que constituye hoy la escuela positiva del derecho penal, en la cual se afirma que las inclinaciones mórbidas de todos los individuos anormales, son una consecuencia de su organización física y psíquica, que es esencialmente diversa de aquella del hombre normal, por esta razón la escuela moderna al tratar de estudiar, como hacía la antigua, el delito en abstracto estudia al delincuente en su morfología y en sus funciones, comparándolas con las de tipo normal social, de la que resulta... la nueva doctrina que conforma la "historia natural del hombre delincuente" (Herrera, 1924, p. 503).

En Bogotá, además de Putnam, existieron otros, especialmente médicos y abogados partidarios de la nueva escuela: Pedro Pablo Anzola, Vicente Duque, Cayetano Méndez, Martín Camacho, Ricardo Fajardo, Pedro Villamizar, Miguel Jiménez López, Juan Triana, Eliseo Montaña, Alfonso Castro, Pablo Llinás, Jorge Bejarano, Luis López de Mesa, entre otros. Según Vásquez (2015), en este momento se presenta una serie de discusiones en la justicia de orden práctico, legal y teórico, con relación a la responsabilidad penal, y civil y una crítica a la teoría penal clásica. Conforme a la autora, los dictámenes médico legales conceden a los médicos la autoridad máxima a la hora de pronunciar un veredicto sobre el estado mental del sujeto, especialmente después de la reforma de 1936.

En Colombia, muchos médicos y sociólogos hicieron eco de este complejo aparato conceptual. Utilizaron el concepto de degeneración para observar y elaborar descripciones médicas, biológicas y sociológicas, que fueron consideradas como un fiel reflejo de la realidad y la tragedia de la población colombiana. Quizá el debate más amplio y conocido que tuvo como eje el problema de la degeneración fueron las conferencias organizadas por la Asamblea de Estudiantes de la Universidad Nacional de Colombia en los meses de mayo y junio de 1920, publicados posteriormente bajo el título "Los problemas de la raza en Colombia" (Rojas, 2015, p. 300).

\footnotetext{
8 Ver en Vásquez (2015) la discusión filosófica en Colombia en págs. 65 y siguientes.

9 Vale la pena insistir en la similitud del concepto "libre albedrío" tanto en la escuela clásica como en la Iglesia católica; este hecho permite entender parte de la resistencia a la nueva escuela, considerada materialista en un país católico, conforme a la Constitución Nacional de 1886.
} 
Volviendo al conocimiento de los postulados de la escuela positiva italiana desde finales del siglo XIX, es importante recordar que, según del Valle (2015), algunos funcionarios judiciales e incluso abogados acudieron a ese conocimiento desde muy temprano, para fundamentar ciertas peticiones ante el poder judicial.

En Antioquia, el siguiente dictamen muestra cómo los médicos legistas mezclan los postulados de la escuela clásica con los de la escuela positiva italiana.

En virtud de detenido estudio del estado mental de [nombre del sindicado del delito, en este caso homicidio] teniendo en cuenta la constancia de los autos y los antecedentes hereditarios y personales que le acompañan, conceptuamos que dicho [...] es un degenerado con estigmas marcados, sobre todo intelectuales y morales. En efecto, aparte de ser un analfabeto completo por falta de educación, siquiera mediocre en sus facultades mentales y morales tiene un grado de inteligencia mínimo para distinguir la verdad del error y un conocimiento vago del bien y del mal para determinar libremente su voluntad, a fin de ejecutar actos morales completos; por lo cual está incluido en el grupo de los imbéciles... (A. H. J. A. Documento 12.926, p. 37).

Para los positivistas el criminal era un anormal, cuyos signos estaban en él o en su familia. Entre los factores que se tuvieron en cuenta estaban: los orgánicos, como una defectuosa conformación craneana, una lesión, la epilepsia, la artritis, el bocio, desórdenes nutritivos, la sífilis y una enfermedad anterior o concomitante, entre otros; las anomalías del comportamiento como la vulnerabilidad, los nervios y las exageraciones del temperamento nervioso; la locura; la esterilidad; la llamada teoría de la degeneración, influida por condiciones como la raza y la herencia mórbida.

Los estigmas físicos; el alcoholismo; el chichismo; las enfermedades mentales; la crueldad con los animales; el homosexualismo; el fetichismo; el sadismo; la falta de educación; la miseria; los factores ambientales; la estatura; la vagancia; el sonambulismo; la mendicidad; los juegos ilícitos; el proxenetismo y la falta de un trabajo legal, entre otros. Algunos de esos factores eran referidos, según Vilar (1939, p. 31) de la siguiente forma: "Especificación de los antecedentes morbosos de familia, que se determinarán en los campos somático, funcional fisiológico y psíquico..." También "Cuantía de conocimientos o de experiencias en las ideas fundamentales: el mundo, el hombre y Dios". El dictamen médico legal sobre el estado mental de un acusado en un proceso tramitado en Antioquia en 1931, describe mucho de lo antes expresado:

[...] conocerlo en su fisonomía psíquica y social para observar si ha revelado o no ser hombre de naturaleza degenerada; seguirlo paso a paso, en sus íntimas relaciones con el menor Múnera para justificar la conclusión de que aquel hombre sí es un invertido sexual constitucional capaz, por este o por aquel motivo, de hacer desaparecer violentamente al sujeto de su desviada pasión y, finalmente, estudiarlo consultando los factores antropológicos que pudieron influir directa o indirectamente en su criminalidad...1) Carlos Cano tiene ligeros estigmas degenerativos; 2) Es hombre de 
bajo nivel mental y muy ignorante; 3) Su sentido moral es obtuso, así lo manifiesta su conducta con la familia; 4) Es un invertido sexual constitucional; 5) Es masoquista; 6) Hay en el expediente la relación de algunos hechos que tienen cierto matiz sadista pero insuficiente por si sólo para conceptuar que lo sea (Citado en Calderón, 2004, p. 47). Negrillas en el texto.

Después de varios intentos se dictó la Ley 95 de 1936 contentiva del Código Penal, vigente a partir de 1938. En este código según Calderón (2004), se impuso Ferri con su teoría plurifactorial, es decir, que tanto los factores biológicos, como los físicos y sociales inciden en la delincuencia.

La escuela clásica ve en el delincuente un hombre normal. La escuela clásica considera que la pena produce los efectos en todas las personas en quienes sea aplicada. La escuela clásica sobre el libre albedrío basa la responsabilidad moral. La escuela clásica pretende retribuir moralmente la falta administrando dosificada la pena. Dentro de la práctica de la escuela clásica el juez condena e ignora definitivamente los resultados que la pena haya producido en la persona del penado...El principio fundamental que informa la escuela positivista presenta el delito como un hecho natural...rechaza la delincuencia como abstracción y estudia la personalidad valora sus hechos y los motivos determinantes de ellos, para averiguar la peligrosidad del agente activo y pone en práctica medios conducentes para la defensa de la sociedad y para la reparación de los daños que hayan causado. La escuela positivista encuentra, mediante las comprobaciones de las ciencias, que el delincuente es persona anormal cuando menos en el mismo momento de ejecutar el hecho delictuoso. La escuela positivista encuentra a favor del estudio de la personalidad del delincuente, que una misma pena produce efectos diversos y contradictorios, aplicada a personas distintas...La retribución moral basada sobre el libre albedrío es un postulado de orden filosófico y religioso; aplicarlo en asuntos penales es debilitar la defensa de la sociedad por abandono del plano científico en que estos asuntos deben ser considerados...La escuela positiva acepta que se sancione la criminalidad revelada por actos externos y sin hecho acompañado de la criminalidad, siempre que se compruebe la peligrosidad del mismo agente ... (Vilar, 1939, p. 10). Negrilla fuera del texto.

No fue fácil instaurar la Ley 95 de 1936. El nuevo código estaba influenciado por los planteamientos de la escuela positiva italiana, particularmente por su propuesta de la personalidad del delincuente y las medidas de seguridad como opción de pena. Muchos de los elementos determinantes de la personalidad del delincuente que llevaban a estas medidas de seguridad eran dictaminados por los médicos adscritos a Medicina Legal, a través de un dictamen médico legal sobre el estado mental del acusado. En su calidad de peritos médicos, los médicos legistas acreditaban ante el juez la personalidad del delincuente dentro de ciertos procesos penales.

De cada uno de los postulados de la escuela positiva surge la necesidad de estudiar de manera integral la persona del delincuente, de valorar los motivos determinantes de sus actos antisociales, de observar el medio físico y social dentro del cual vive y de apreciar sus antecedentes hereditarios morbosos, para reducirlo a la impotencia, 
someterlo a curación y observación, darle libertad condicional o establecer en su favor el perdón judicial, objetivos que fundamentan en esta escuela los medios preventivos, reparatorios, represivos y eliminatorios que constituyen la estructura de la defensa social y la reparación del daño realizado (Vilar, 1939, p. 16).

El dictamen médico-legal posibilitó lo anterior, en especial el dictamen médico legal sobre el estado mental del acusado. Además, los artículos 36 a 40 regulaban las circunstancias de mayor o menor peligrosidad, entre las que se encontraban los antecedentes de depravación y libertinaje. Una vez vigente el Código Penal de 1936, los médicos legistas dictaminarían el estado psico-físico del acusado, haciendo énfasis en si el acusado padecía alguna anomalía psíquica. Pero, es posible que la famosa discusión cediera en intensidad. El concepto de "ciencia" que fue dominante en este período histórico ahogó conflictos avivados por el fuego de la religión, como sucedió con el libre albedrío. El número de individuos sujetos a la ley penal amplió el control social y se hace evidente la afirmación de Olmo (2005) en el sentido de que existen varios sistemas de control social, por eso "la pena con su propósito de prevención general positiva, contribuye a la confirmación y el aseguramiento de los otros sistemas de control social".

\section{Conclusión}

El derecho penal es un sistema de control social, que fue ejercido en Antioquia, no solo desde el orden jurídico, sino desde saberes como la medicina legal. El tipo de cientificidad dominante entre 1914 y 1938 fue muy influyente en el estatuto penal colombiano de 1936. Desde la última parte del siglo XIX se venía presentando el fenómeno de la medicalización de las prácticas médicas. La medicina legal, como especialidad de la medicina "científica", fue necesaria en la realización del dictamen pericial médico. Pero en el caso del dictamen médico legal sobre el estado mental de un acusado es necesario tener en cuenta que, según Vásquez (2015), la medicina legal se apropió de los problemas mentales. Ahora bien, las nuevas ciencias, entre ellas las señaladas por la escuela positiva italiana, por un lado, y la teoría de la degeneración, por otro lado, terminaron impactando la medicina legal y por esta vía a algunas conductas de los acusados en los procesos penales, especialmente las del hombre considerado anormal.

Lo anterior posibilitó cambiar un conocimiento muy importante en muchos procesos judiciales criminales, como en el caso de la locura. Las discusiones entre médicos y abogados de ese momento histórico favorecieron la apropiación de este conocimiento.

El Código Penal de 1936, que entró a regir en 1938, reemplazó al Código Penal de 1890. Pero esa sustitución no fue fácil. Todavía se observa el pensamiento 
clásico y a pesar de que eran conocidos en el país los postulados de la escuela positiva italiana solo se pudieron imponer, en parte, en 1936 con el nuevo Código Penal.

\section{Referencias bibliográficas}

Agudelo, N. (2002). Grandes corrientes del derecho penal. Escuela positivista. 7. edición. Bogotá: Editorial TEMIS.

Agudelo, N. (2008). Grandes corrientes del derecho penal. escuela clásica. 3. ${ }^{a}$ ed. Bogotá: Temis Aguilar, D.: El control social y el ordenamiento jurídico una conceptualización desde el objeto de estudio de la sociología jurídica, en Contribuciones a las Ciencias Sociales, mayo 2010, www.eumed.net/rev/ cCCSs/08/daa4.htm

Aguilar, D.: El control social y el ordenamiento jurídico una conceptualización desde el objeto de estudio de la sociología jurídica, en Contribuciones a las Ciencias Sociales, mayo 2010. Disponible en http:// www.eumed.net/rev/cccss/08/daa4.htm

Calderón, L. (2004). La escuela positiva italiana en la objetivación del criminal en Antioquia (1893-1936). Monografía para optar al título de historiadora. Universidad Nacional. Escuela de Historia y Escuela de Estudios Filosóficos y Culturales. Medellín

Caponi, S. (2009). Para una genealogía de la anormalidad: la teoría de la degeneración de Morel. Scientiæ Zudia, São Paulo, v. 7, N. ${ }^{\circ}$ 3, pp. 425-445.

Decreto 592 de 1905. Disponible en: www.mineducacion.gov.co/1759/w3-article-102519.html

Del Valle, P. (2010) La medicalización de la justicia en Antioquia (1887-1914). Medellín: Editorial Universidad de Antioquia.

Del Valle, P. (2010). El dictamen médico-legal en Antioquia (1887-1914). Medellín: Canal Universitario de Antioquia, pp. 343-357.

Del Valle, P. (2015). Amores criminales. Un caso de parricidio en Colombia. En M. Hering \& N.A. Rojas (Ed.), Microhistorias de la transgresión (pp. 197-229). Bogotá: Editorial Universidad del Rosario. Ediciones Universidad Cooperativa de Colombia. Centro de Estudios Sociales (CES) Universidad Nacional de Colombia

Documento 12.926 (1916). A. H. J. A. Laboratorio de Fuentes Históricas de la Universidad Nacional, sede Medellín

Documento N. ${ }^{\circ} 11222$ (1936) del Archivo Histórico Judicial (A. H. J. A.). Laboratorio de Fuentes Históricas de la Universidad Nacional, sede Medellín

Foucault, M. (1980). La verdad y las formas jurídicas. Barcelona: Gedisa. Ley 95 de 1936, disponible en: www.suin-juriscol.gov.co/viewDocument.asp?id=1791348

Guerrero, D. (2012). La encíclica Veritatis splendor de Juan Pablo II: lectura desde la educación. Disponible en file:///C:/U/Downloads/Dialnet-LaEnciclicaVeritatisSplendorDeJuanPabloII-4409786. pdf 2012

Herrera, J. D. (1924). Informe Académico. Repertorio de Medicina y Cirugía, v. 15, n. 178, pp. 503-509 
Ley 35 de 1929. Disponible en: www.mineducacion.gov.co/1621/article-103004.html

Ley 39 de 1920. Disponible en: www.mineducacion.gov.co/1621/articles-102484_archivo _pdf

Ley 67 de 1920. Disponible en: www.suin-juriscol.gov.co/viewDocument.asp?id=1789714

Ley 67 de 1935. Disponible en www.mineducacion.gov.co/1621/articles-102486 _archivo _ pdf.

Ley 83 de 1914 disponible en: www.mineducacion.gov.co/1621/articles-102458 _ archivo _ pdf

Ley 85 de 1922. Disponible en: www.mineducacion.gov.co/1759/w3-article-102489.htm

Lombroso, C. (1943). Los criminales. Buenos Aires: Editorial Tor.

Márquez, J. (2011). El charlatanismo en el proceso de constitución del poder y de la profesión médica en Colombia, 1880-1921 en Quintero, J. (coord.). El nacimiento de la libertad en la península Ibérica y Latinoamérica. Actas del VI Congreso Internacional de AHILA, pp. 553-560.

Márquez, J. (2016). El médico de oficio en Colombia en las décadas de 1920 y 1930. En Revista Mundos do Trabalho, vol. 7, $\mathrm{N}^{\circ}$. 13, janeiro-junho de 2015, pp. 85-104.

Moulines, C. La génesis del positivismo en su contexto científico. Barcelona. Universidad de Barcelona. Año IV. Número: 19. 1979 en http://www.ub.edu/geocrit/geo19.htm

Olmo, P. O. El concepto de control social en la historia social. Estructuración del orden y respuestas al desorden. Historia Social 5 (2005), pp. 73-91.

Putnam, C.E. (1894). Conferencia dada por Carlos E. Putnam, en el Colegio Mayor de Nuestra Señora del Rosario, en la noche del 17 de junio. Anales de la Academia de Medicina de Medellín, v. 5, n. 7-8, pp. 193-221.

Rocco, A. (1982). El problema y el método de la ciencia del derecho penal. Bogotá: Editorial Temis

Rodríguez, E. (1927). Constitución y Códigos de Colombia. Bogotá: Librería América. 1927.

Rojas, N. A. (2015). El delincuente epiléptico. El caso de Braulio Ramos o el hombre tigre. En M. Hering \& N. A. Rojas (Ed.), Microhistorias de la transgresión (pp. 275-318). Bogotá: Editorial Universidad del Rosario. Ediciones Universidad Cooperativa de Colombia. Centro de Estudios Sociales (CES) Universidad Nacional de Colombia.

Salcedo, H. (2002). Epistemología o filosofar sobre la ciencia. Medellín: Ediciones Unaula.

Vásquez, M. (2015). Degenerados, criminosos e alienados. Para uma história do conceito de degeneração na Colômbia, 1888-1950. Tese de doutorado. Programa de Pós-Graduação Interdisciplinar em Ciências Humanas. Universidade Federal de Santa Catarina (Brasil).

Vilar, E. (1939). El nuevo Código Penal y el modo de interpretarlo científicamente. Bogotá: Librería Colombiana. Camacho Roldán \& Cía. S. A. 